\section{Commentary: Autologous mitochondrial transplantation: An exciting innovation that needs evidence of efficacy}

\author{
David J. Barron, MD, FRCS(CT), and \\ John G. Coles, MD, FRCSC
}

Guariento and colleagues ${ }^{1}$ describe a pilot clinical trial of a conceptually innovative form of regenerative therapyautologous mitochondrial transplantation (MT)-in ischemia-reperfusion injury. This approach extends an earlier report from this group describing the first inhuman use of autogenous MT in extracorporeal membrane oxygenation-dependent patients. ${ }^{2}$ The authors should be credited as the primary innovators of MT for cardiac regeneration and this study serves as the next step in the translation of this approach after extensive preclinical studies. However, this study is limited by the wide variability in the nature and extent of the ischemia-reperfusion injury, difficulty in defining a control group, and the limited evidence of functional benefit. Although this particular study cannot be construed as providing evidence of efficacy or even safety of MT (as acknowledged by the authors), this work further rationalizes the implementation of follow-up Phase I and II studies, preferably involving multicenter patient recruitment. The exciting promise of this approach, coupled with the urgent unmet need posed by heart failure in pediatric patients, demands this type of investment in broader rigorous investigations.

Preclinical reports have demonstrated an incontrovertible efficacy signal associated with MT in multiple organ systems, including heart, lung, neurological tissue, liver, and kidney, as well as in sepsis. ${ }^{3-7}$ It will be fascinating to

From the Division of Cardiovascular Surgery, The Labatt Family Heart Centre, The Hospital for Sick Children, University of Toronto, Toronto, Ontario, Canada.

Disclosures: The authors reported no conflicts of interest.

The Journal policy requires editors and reviewers to disclose conflicts of interest and to decline handling or reviewing manuscripts for which they may have a conflict of interest. The editors and reviewers of this article have no conflicts of interest.

Received for publication Nov 15, 2020; revisions received Nov 15, 2020; accepted for publication Nov 17, 2020; available ahead of print Nov 24, 2020.

Address for reprints: David J. Barron, MD, FRCS(CT), Division of Cardiovascular Surgery, The Labatt Family Heart Centre, The Hospital for Sick Children, 555 University Ave, Toronto, Ontario M5G 1X8 Canada (E-mail: david.barron@ sickkids.ca).

J Thorac Cardiovasc Surg 2021;162:1004-5

0022-5223/ $\$ 36.00$

Crown Copyright $(2020$ Published by Elsevier Inc. on behalf of The American Association for Thoracic Surgery

https://doi.org/10.1016/j.jtcvs.2020.11.067

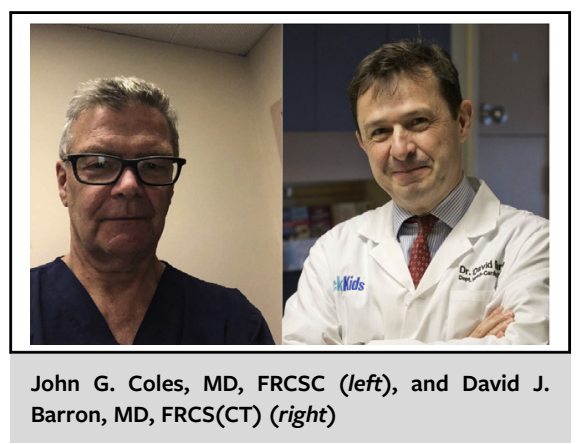

CENTRAL MESSAGE

Mitochondrial transplantation shows exciting promise for cardiac regeneration but still needs proof of safety and efficacy.

determine the many unsolved scientific questions concerning MT, such as the precise mechanism of action, the optimal routes and methods of administration, and the specificity of disease indications such as the beneficial ventricular remodeling effects already shown by the Boston group. ${ }^{8}$ The universal benefits of improved mitochondrial function include increased adenosine triphosphate generation, mitigation of free radical stress, augmented mitochondrial biogenesis, improved metabolism, cytoprotective signaling properties, and anti-inflammation. Transplantation of respiration-competent allogenic mitochondria reduced multiorgan dysfunction in a rat sepsis model in part via attenuation of the inflammatory cytokine response, ${ }^{7}$ suggesting the theoretical value of preemptive, systemically administered MT trial designs for extracorporeal membrane oxygenation indications.

The options for regenerative biological therapy in cardiac indications are wide-ranging and evolving, and include transplantation of mesenchymal stem cells and exosomes from various sources. It is established that most of the benefit from cellular transplantation depends on paracrine factors because intact cellular retention is limited. It is plausible that the benefits of MT may depend on specific components or the secretome contained within the mitochondria, not necessarily on the intact, complex microstructure per se. To add further mechanistic complexity, the very process of cellular internalization of mitochondria may activate stressresponse signaling pathways as a result of the release of damage-associated molecular patterns. ${ }^{9}$ In the fascinating biological process of nanotube formation, mitochondria cell-to-cell transfer can occur spontaneously following tissue injury from healthy to injured cells, ${ }^{5}$ or via donation from 
transplanted mesenchymal stem cells. ${ }^{10}$ Thus, mitochondrial restitution may be a unifying feature of both mesenchymal stem cell-mediated and exogenous forms of MT.

These seminal studies in MT present many exciting basic science questions that are yet to be solved, which in turn will help to refine translational implementation to the benefit of patients with congenital heart disease. More extensive studies are needed to investigate whether there are genuine clinical benefits.

\section{References}

1. Guariento PB, Doulamis LP, Blitzer D, Ferraro AM, Harrild DM, Zurakowski D, et al. Autologous mitochondrial transplantation for cardiogenic shock in pediatric patients following ischemia-reperfusion injury. J Thorac Cardiovasc Surg. 2021;162:992-1001.

2. Emani SM, Piekarski BL, Harrild D, Del Nido PJ, McCully JD. Autologous mitochondrial transplantation for dysfunction after ischemia-reperfusion injury. J Thorac Cardiovasc Surg. 2017;154:286-9.

3. Konari N, Nagaishi K, Kikuchi S, Fujimiya M. Mitochondria transfer from mesenchymal stem cells structurally and functionally repairs renal proximal tubular epithelial cells in diabetic nephropathy in vivo. Sci Rep. 2019;9:5184.

4. Liu K, Guo L, Zhou Z, Pan M, Yan C. Mesenchymal stem cells transfer mitochondria into cerebral microvasculature and promote recovery from ischemic stroke. Microvasc Res. 2019;123:74-80.

5. Moskowitzova K, Orfany A, Liu K, Ramirez-Barbieri G, Thedsanamoorthy JK, Yao R, et al. Mitochondrial transplantation enhances murine lung viability and recovery after ischemia-reperfusion injury. Am J Physiol Lung Cell Mol Physiol. 2020;318:L78-88.

6. Shi X, Bai H, Zhao M, Li X, Sun X, Jiang H, et al. Treatment of acetaminopheninduced liver injury with exogenous mitochondria in mice. Transl Res. 2018;196: 31-41.

7. Zhang Z, Yan C, Miao J, Pu K, Ma H, Wang Q. Muscle-derived mitochondrial transplantation reduces inflammation, enhances bacterial clearance, and improves survival in sepsis. Shock. October 14, 2020 [Epub ahead of print].

8. Weixler V, Lapusca R, Grangl G, Guariento A, Saeed MY, Cowan DB, et al. Autogenous mitochondria transplantation for treatment of right heart failure. J Thorac Cardiovasc Surg. August 10, 2020 [Epub ahead of print].

9. Krysko DV, Agostinis P, Krysko O, Garg AD, Bachert C, Lambrecht BN, et al Emerging role of damage-associated molecular patterns derived from mitochondria in inflammation. Trends Immunol. 2011;32:157-64.

10. Voloboueva LA, Giffard RG. Inflammation, mitochondria, and the inhibition of adult neurogenesis. J Neurosci Res. 2011;89:1989-96.
See Article page 992.

\section{Commentary: Energizing with ATP may be critical in ischemic pediatric hearts}

Mohamed Abdullah, MD, $\mathrm{PhD}$, and Sunjay Kaushal, MD, PhD

Ischemia-reperfusion injury (IRI) underlies the mechanism of myocardial dysfunction in various cardiac surgery settings. Altered mitochondrial architecture and function are hallmarks of IRI. ${ }^{1}$ Serving as the final arbiter of life and

From the Division of Cardiac Surgery, Ann \& Robert H. Lurie Children's Hospital of Chicago, Chicago, Ill.

Disclosures: The authors reported no conflicts of interest.

The Journal policy requires editors and reviewers to disclose conflicts of interest and to decline handling or reviewing manuscripts for which they may have a conflict of interest. The editors and reviewers of this article have no conflicts of interest.

Received for publication Jan 5, 2021; revisions received Jan 5, 2021; accepted for publication Jan 6, 2021; available ahead of print Jan 20, 2021.

Address for reprints: Sunjay Kaushal, MD, PhD, Division of Cardiac Surgery, Ann \& Robert H. Lurie Children's Hospital of Chicago, 225 E Chicago Ave, Chicago, IL 60611 (E-mail: skaushal@luriechildrens.org).

J Thorac Cardiovasc Surg 2021;162:1005-6 $0022-5223 / \$ 36.00$

Copyright (c) 2021 Published by Elsevier Inc. on behalf of The American Association for Thoracic Surgery

https://doi.org/10.1016/j.jtcvs.2021.01.024

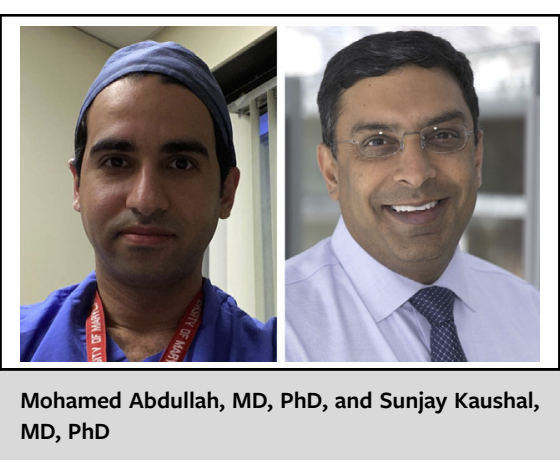

CENTRAL MESSAGE

Mitochondrial transfer may carry some benefit for the ischemic myocardium. Further studies are necessary to prove the efficacy and determine the applicability of this approach.

death, mitochondria are not only required to generate ATP but also can trigger apoptosis and necrosis. ${ }^{2}$

The current study by Guariento and colleagues ${ }^{3}$ demonstrates the potential effectiveness of autologous mitochondrial transfer (MT) therapy prepared from nonischemic skeletal muscles and injected directly into the ischemic myocardium in pediatric patients who require 